\title{
Association of markers of chronic viral hepatitis and blood mercury levels in US reproductive-age women from NHANES 2001-2008: a cross-sectional study
}

\author{
Mary C Sheehan ${ }^{1 *}$, Thomas A Burke ${ }^{1}$, Patrick N Breysse ${ }^{2}$, Ana Navas-Acien², John McGready ${ }^{3}$ and Mary A Fox ${ }^{1}$
}

\begin{abstract}
Background: Methylmercury (MeHg) is a neurotoxin primarily found in seafood; exposures in reproductive-age women are of concern due to vulnerability of the developing fetus. MeHg is mainly eliminated via an enterohepatic cycle involving the liver and gallbladder. Dysfunction in these organs has been associated with slower MeHg elimination in laboratory animals. We hypothesized that women testing positive for chronic hepatitis B (HBV) or C $(\mathrm{HCV})$, both associated with risk of longer-term liver and gallbladder impairment, would have higher total blood mercury (TBHg) concentrations than those negative for the viruses, reflecting slower MeHg elimination.

Methods: Geometric mean (GM) TBHg levels from a representative sample of over 5,000 seafood-consuming, reproductive-age women from eight years (2001-2008) of the US NHANES survey were compared by viral hepatitis status (as determined by serological assay) using multiple linear regression. Adjustment was made for estimated MeHg intake from seafood consumption, social and demographic variables and other predictors.

Results: Women with chronic HBV had $1.52(95 \% \mathrm{Cl} 1.13,2.05, \mathrm{p}<0.01)$ times the GM TBHg of women who had not come into contact with the virus. The positive association was strongest in those with most severe disease. A modest negative association was found with HCV markers.

Conclusions: While study design prevents inferences on causality, the finding that MeHg biomarkers differ by hepatitis status in this population suggests viral hepatitis may alter the pace of MeHg elimination. Offspring of HBV-infected seafood-consuming women may be at higher risk of MeHg-induced developmental delays than offspring of those uninfected. Possible reasons for the unanticipated negative association with HCV are explored.
\end{abstract}

Keywords: Biomonitoring, Developmental neurotoxicity, Hepatitis, Mercury, NHANES, Reproductive-age women, Seafood, Susceptibility

\section{Background}

Methylmercury (MeHg) is a neurotoxin widely present in the environment to which the developing fetus is acutely vulnerable [1]. The primary exposure source and pathway for this sensitive population is maternal seafood consumption [2]. Numerous countries have issued commercial seafood advisories for reproductive-age women [3] with the goal of minimizing $\mathrm{MeHg}$ intake and

\footnotetext{
* Correspondence: msheehan@jhsph.edu

'Department of Health Policy and Management, Johns Hopkins Bloomberg School of Public Health, Baltimore, MD, USA

Full list of author information is available at the end of the article
}

protecting offspring from the verbal, spatial and finemotor skill delays associated with $\mathrm{MeHg}$-induced developmental neurotoxicity [2].

Individuals are known to differ in susceptibility to health risks from contaminants such as $\mathrm{MeHg}[4,5]$. Variability has been observed in MeHg's toxicokinetic processing as well as its neurotoxic effects in association with differences in maternal age [6], genetic polymorphisms in the glutathione (GSH) system [7], nutrient intake $[8,9]$ and the social environment $[10]$, among other factors. Further study of such effect modifiers has been called for [11,12]. In particular, while substantial 
variability has been demonstrated in MeHg's elimination phase $[1,13]$, few epidemiological studies have examined factors that modify the pace of elimination. Infants born to seafood-consuming reproductive-age women who are slow eliminators of $\mathrm{MeHg}$ may be at higher risk of neurological harm.

$\mathrm{MeHg}$ is eliminated primarily (more than two-thirds) via the biliary pathway [14]. Animal studies have shown that elimination of $\mathrm{MeHg}$, like many nutrients, drugs and xenobiotics, involves an enterohepatic (EH) cycle [15]. According to Dutczak et al. [16]:

"Reabsorption of solutes from bile... functions to conserve endogenous compounds but can also prove deleterious by impeding the clearance of toxic compounds... $\mathrm{MeHg}$... [is] believed to undergo extensive enterohepatic cycling... [in which] the gallbladder ... reabsorbs $\mathrm{MeHg}$ reducing the amount delivered to the GI tract, and therefore the amount that can be eliminated..."

$\mathrm{EH}$ reabsorption of $\mathrm{MeHg}$ helps explain its relatively long half-life (averaging about 50-70 days) in the human body $[15,17]$. Factors such as prescription drugs, age, and disease have been observed to speed or slow the pace of EH cycling $[18,19]$. In particular, it may be hypothesized that dysfunction in the liver and gallbladder, key organs in the $\mathrm{EH}$ cycle, may contribute to the wide variability in $\mathrm{MeHg}$ half-life observed (from 32 to 189 days) [17]. Experimental research has found that depletion of GSH, which can occur when the liver functions poorly, decreased biliary excretion of $\mathrm{MeHg}$ and increased its half-life in male rats [20]. In biliary excretion-deficient male rats lower bile flow was associated with a 2.5-times longer $\mathrm{MeHg}$ elimination time than in control animals [21]. In humans, liver that is damaged by inflammation, fibrosis (hardened, fibrous tissue) or cirrhosis (replacement of healthy by scar tissue) has a lower share of normallyfunctioning tissue than healthy liver [22]; blood flow and metabolism are reduced, metabolic byproducts may be less efficiently transported into bile, and bile less efficiently cleared [22,23]. Such conditions may affect hepatobiliary clearance by decreasing uptake of substances into hepatocytes, changing metabolism in hepatocytes, or decreasing elimination into bile [18].

The most common cause of liver disease is viral hepatitis $[24,25]$. In the US, $4.9 \%$ of the population has been exposed to hepatitis $\mathrm{B}(\mathrm{HBV})$ and the prevalence of chronic $\mathrm{HBV}$ is $0.3 \%$; hepatitis $\mathrm{C}(\mathrm{HCV})$ exposure is estimated to be $1.8 \%$ and prevalence of chronic disease is $1.6 \%$ [25]. The common general characteristics of both chronic $\mathrm{HBV}$ and $\mathrm{HCV}$ include premature death of hepatocytes, inflammation, and fibrosis [26]. Up to $30 \%$ of HBV carriers and $65 \%$ of the HCV-infected go on to develop cirrhosis (the highest stage of fibrosis) and/or hepatocellular carcinoma (HCC) [24,27]. Chronic hepatitis can also lead to structural changes in biliary elimination architecture $[18,27,28]$. Specifically, viral hepatitis has been associated with thickening of the gallbladder wall and development of gallbladder sludge [29], presence of gallstones [30], and gallbladder and bile duct polyps and cancers [31,32] in epidemiological studies in varied populations. Bile acids, which also undergo $\mathrm{EH}$ cycling, have been found to be elevated in serum in cases of hepatitis-associated liver dysfunction [27].

Based on this literature, we hypothesized that chronic viral $\mathrm{HBV}$ or $\mathrm{HCV}$ could interfere with biliary elimination of $\mathrm{MeHg}$, and that this would be reflected in higher circulating blood levels of mercury in those with these diseases compared to those without. As reference scenarios, we further hypothesized no difference in blood mercury concentrations between those with and those without the acute-only and self-limiting hepatitis A (HAV), and between those vaccinated and those unvaccinated for $\mathrm{HBV}$.

\section{Methods}

\section{Study population and data}

We tested this hypothesis in a large sample of reproductive-age seafood-consuming women who participated in the National Health and Nutrition Examination Survey (NHANES). NHANES is a complex, stratified multi-stage sample designed to be representative of the US non-institutional population, implemented by the CDC's National Center for Health Statistics (NCHS). Data collection consists of an in-person interview to gather demographic, socioeconomic and other information, and a physical examination. The exam includes a dietary questionnaire and laboratory testing of blood, urine and other tissue samples for a standard biochemical and disease panel and numerous chemical toxicants. In order to have a sufficient sample size to stratify by gender, lifestage, seafood intake, and hepatitis status, we pooled data from 2001 to 2008, the most recent four NHANES cycles with full data available. The total screened sample for the eightyear period was 50,822; the average response rate for the interview was $80 \%$, and for the exam was $77 \%$. We analyzed data for 7,870 women aged 16-49 who completed the NHANES questionnaire, examination and laboratory components. We eliminated women who answered negatively to having consumed seafood in the last 30 days (as these women were less likely to have detectable blood mercury concentrations), as well as those missing blood mercury measurements and other covariates of interest. The total number of study participants was 5,088 for the HBV analysis; 5,071 for HCV; and 4,104 for HAV (HAV assay results were available for 2001-2006 only). Informed-consent was provided by all participants, and 
the survey protocol was approved by the NCHS institutional review board.

\section{Blood mercury measurement}

The main dependent variable was the concentration of total blood mercury (TBHg), a validated proxy measure for recent $\mathrm{MeHg}$ intake $[33,34]$. TBHg was measured in micrograms per liter $(\mu \mathrm{g} / \mathrm{L})$ of whole blood using cold vapor atomic absorption spectrometry (2001-2002) and inductively-coupled plasma dynamic reaction cell mass spectrometry (2003-2008). Analysis of samples was done at the CDC's Division of Laboratory Sciences, National Center for Environmental Health (NCEH). All medical and phlebotomy staff were trained and used standardized protocols. Other than measurement technique, no changes in lab procedures were noted over the study period. Quality assurance included use of blind split samples, repeat testing and use of international standard rules for quality control. NCEH staff verified extremely high and low values and performed consistency checks. The limit of detection was between $0.14 \mu \mathrm{g} / \mathrm{L}$ and $0.33 \mu \mathrm{g} / \mathrm{L}$.

\section{Determination of hepatitis status and study hypotheses}

The main independent variable for this analysis was hepatitis status. Hepatitis status was determined using CDC case definitions [35,36], the hepatitis literature, and hepatitis assay results for our 2001-2008 sample of reproductive-age women (Table 1). For the women in this NHANES sample, laboratory results analyzed by the CDC's Division of Viral Hepatitis were available for a sub-set of the assays noted in the CDC chronic HBV and $\mathrm{HCV}$ case definitions: hepatitis $\mathrm{B}$ core antibody (anti-HBc); hepatitis B surface antibody (anti-HBs); hepatitis B surface antigen (HBsAg), and hepatitis C antibody (anti-HCV). Results were also available for total hepatitis A antibody (anti-HAVT). We examined three models.

In the Hepatitis A model, comparison was made between women who tested positive for total hepatitis A antibody (anti-HAVT) - which indicates current or past exposure to either the HAV virus or the vaccine [24] and the reference (negative anti-HAVT) group. AntiHAVT was determined using a solid-phase competitive enzyme-based immunosorbent assay (ELISA). Because the acute-only HAV infection carries low risk of longerterm liver damage, in this model we hypothesized there would be no association between TBHg concentrations and positive anti-HAVT status.

HBV has a more complex natural history, with four recognized stages of disease: virus incubation, immune response, recovery (inactive carrier status), and development of immunity; while an average of $1-2 \%$ of inactive carriers seroconvert and develop natural immunity annually, about one-third may at some point re-activate to active disease $[24,26]$. Positive anti-HBc accompanied by positive $\mathrm{HBsAg}$ indicates chronic active disease, while in combination with negative HBsAg it indicates likely inactive carrier status. Anti-HBs is a marker of immunity; in combination with anti-HBc this is likely to be natural immunity, while anti-HBs positive alone signals probable vaccine-derived immunity $[24,26,37]$. Based on these serological assays we defined three HBV-exposed groups:

- Current HBV: women positive for anti-HBc and negative for anti-HBs, including both those HBsAg positive (likely to have active disease) and those HBsAg negative (likely to be inactive carriers);

Table 1 Hepatitis groups, available NHANES test results and number of women in study sample

\begin{tabular}{|c|c|c|}
\hline Hepatitis group & NHANES tests available and results to be in group & No. women in sample \\
\hline \multicolumn{3}{|l|}{ Hepatitis A } \\
\hline Current or past infection or immunization & Anti-HAVT positive & 1,466 \\
\hline No infection or immunization & Anti-HAVT negative & 2,638 \\
\hline \multicolumn{3}{|l|}{ Hepatitis B } \\
\hline Current infection & Anti-HBc positive, anti-HBs negative & 40 \\
\hline - Active infection & As for current infection, plus $H B s A g$ positive & 11 \\
\hline - Inactive carrier & As for current infection, plus HBsAg negative & 29 \\
\hline Resolved (past) infection & HBsAg negative, anti-HBc positive, anti-HBs positive & 145 \\
\hline Immunized & HBsAg negative, anti-HBc negative, anti-HBs positive & 1,520 \\
\hline No infection or immunization & HBsAg negative, anti-HBC negative, anti-HBs negative & 3,383 \\
\hline \multicolumn{3}{|l|}{ Hepatitis C } \\
\hline Current or past infection & Anti-HCV positive & 70 \\
\hline No infection & Anti-HCV negative & 5,001 \\
\hline
\end{tabular}


- Recovered HBV: women positive for both anti-HBc and anti-HBs, denoting past infection and development of natural immunity to the virus; and

- Immunized HBV: women positive for anti-HBs and negative for anti-HBc, indicating vaccine-derived immunity.

Each HBV-exposed group was compared to the reference group negative for anti-HBc, anti-HBs and $\mathrm{HBsAg}$ (i.e., no contact with the virus or vaccine). Anti-HBc was detected using an ELISA (Ortho) in which all reactive specimens were re-tested (the result was positive with at least one reactive re-test). Only positive anti-HBc samples were tested for HBsAg, detected using a sandwich ELISA (Abbott Labs). Anti-HBs was determined using a sandwich solid phase ELISA (AUSAB), with concentration of anti-HBs compared to a standard curve. Because of the elevated risk of longer-term liver and gallbladder damage we hypothesized a positive association between presence of markers for current HBV and TBHg levels. Since the seroconverted remain at elevated risk of developing fibrosis, cirrhosis and HCC over their lifetimes [24], we also hypothesized an association between markers of HBV recovery and TBHg levels. We hypothesized no association between having been vaccinated for HBV and TBHg.

In model $\mathrm{C}$, we compared women testing positive for anti-HCV, indicative of current or past infection $[24,26]$, and the reference uninfected group. Anti-HCV was detected using direct solid-phase ELISA screening, and positives confirmed with recombinant immunoblot assay (Chiron). Due to longer-term liver damage associated with $\mathrm{HCV}$, we hypothesized a positive association between presence of anti-HCV and $\mathrm{TBHg}$ concentrations. There is currently no vaccine for $\mathrm{HCV}$.

\section{MeHg intake and other covariates}

Seafood consumption frequency and species are the main determinants of $\mathrm{MeHg}$ intake in the nonoccupational general human population $[1,2,34]$. The NHANES dietary interview covered consumption frequency of 10 shellfish and 21 finfish species (number of servings over the 30 days prior to the interview). Trained interviewers used a computerized data collection instrument (involving a five-step recall process: quick list, forgotten foods prompt, time and occasion prompt, details prompt, and final probe), along with aids such as photos of different seafood species. Quality control included reconfirming all values over nine servings and review of interviewer audio reports, among other measures. We used these seafood consumption data, along with seafood species-specific mercury concentration data published by the US FDA [38], to calculate estimated $\mathrm{MeHg}$ intake by study participant. $\mathrm{MeHg}$ intake for the six most frequently-consumed species was estimated by multiplying the number of meals for each over 30 days by per-meal mercury values in grams, derived using the FDA average $\mathrm{MeHg}$ concentration for the species (assuming a 170-gram meal size [39]). To estimate $\mathrm{MeHg}$ intake from less commonly-consumed other finfish and shellfish we used average FDA $\mathrm{MeHg}$ concentration values for all finfish and all shellfish, respectively. The results were aggregated by participant and used to adjust the three models for 30-day estimated $\mathrm{MeHg}$ intake from seafood.

Additional independent variables that could potentially confound results were defined based on the mercury literature [34,40-42]. These included household income, education attainment, ethnicity, country of birth, alcohol intake, and body-mass index (BMI). We adjusted each model for other hepatitis viruses, and given co-infection with human immunodeficiency virus (HIV) among some hepatitis-infected groups [43], we also included HIV status as a covariate.

\section{Statistical methods}

To facilitate use of linear regression methods, we logtransformed the right-skewed $\mathrm{TBHg}$ distribution. We employed the back-transformed geometric mean (GM) as a summary statistic, and used $95 \%$ confidence intervals $(95 \% \mathrm{CIs})$ to describe variation. Using bivariate analysis, we summarized GM TBHg concentrations by covariate, and participant characteristics by hepatitis status. We used linear regression analysis to examine relationships between TBHg and hepatitis status defined by the serological markers described. Regression coefficients were back-transformed from the log scale. Our main outcome was the ratio of GM TBHg concentration between women in the defined hepatitis-exposed group to the respective unexposed reference group. A GM $\mathrm{TBHg}$ ratio of greater than 1.0 indicated a positive association, and a GM TBHg ratio of less than 1.0 indicated a negative association. Statistical significance was tested using a two-tailed $t$-test with an alpha level of 0.05 . We adjusted each model for the covariates described using backwards step-wise selection to eliminate covariates ( $p$ value cut-off of less than 0.10 ). In addition, we examined interaction terms to test for effect modification, and performed sensitivity analyses to examine assumptions about seafood intake, the most important driver of TBHg levels. In sensitivity analysis we also examined clinical markers of liver function. We weight-adjusted all analyses to account for over-sampling of underrepresented groups, and used Taylor series linearization for variance estimation as recommended by NCHS. All statistical analyses were performed in Stata (Stata Statistical Software: Release 10, Statacorp, College Station, TX, 2007). 


\section{Results}

\section{Blood mercury concentrations}

The GM TBHg concentration in this population of reproductive-age seafood-consuming women was 1.02 (95\% CI 0.97, 1.08) $\mu \mathrm{g} / \mathrm{L}$ (Table 2). Consistent with the literature $[34,40,42]$, unadjusted GM TBHg concentrations were higher in older women, those of "Other" (Asian, Pacific Islander and Native American) ethnicity, the foreign-born, those with higher household income and education attainment, and those with lower BMI. Women who consumed 5-8 servings of seafood over the month had GM TBHg concentrations almost two times higher than those who consumed 1-4 servings. Those who consumed 9 or more servings had GM TBHg concentrations over two times higher than the 14 serving group. There was a moderate correlation between TBHg and seafood servings (correlation coefficient 0.34 ). Compared to women without exposure to a hepatitis virus, those positive for HAV had similar GM $\mathrm{TBHg}$ concentrations. Those positive for HBV had 1.4 times higher GM TBHg concentrations, and those positive for HCV had 25\% lower GM TBHg concentrations, than those without exposure to a hepatitis virus.

\section{Hepatitis A, B and C status}

Of 4,104 women in the hepatitis A model, 1,466 were positive for anti-HAVT, indicating vaccine-derived or natural immunity (Table 3). Of 5,088 women in the hepatitis $\mathrm{B}$ model, 40 were positive for anti-HBc and negative for anti-HBs, comprising the current $\mathrm{HBV}$ group; 145 were positive for both anti- $\mathrm{HBc}$ and antiHBs, constituting the recovered HBV group; and 1,520 were negative for anti-HBc and positive for anti-HBs, comprising the immunized HBV group. Of 5,071 women in the hepatitis $\mathrm{C}$ model, 70 were positive for anti-HCV. The implied prevalence rates are consistent with the epidemiology literature [25].

Women having had HAV, or having been vaccinated for it, did not differ by age, BMI or alcohol intake from those who had not, however, they did differ by socioeconomic parameters (Table 3). Women having come into contact with the hepatitis B virus (including both current and recovered disease) were on average older (by 6 years) than those without HBV contact and more likely to have lower income and lower education attainment, be of Black or Other ethnicity, and be foreignborn. HBV-positive women also ate slightly $(10 \%)$ more seafood than the sample average, and about $11 \%$ were co-infected with $\mathrm{HCV}$. Those positive for $\mathrm{HCV}$ were older (by 10 years), and more likely to have lower income and lower education attainment compared to women who were negative for HCV. Unlike those positive for $\mathrm{HBV}$, however, women positive for $\mathrm{HCV}$ were more likely to be American-born, to be of mainly White or Black ethnicity, and to consume more alcohol than average. These women ate slightly less (13\%) seafood than average, and about $30 \%$ were co-infected with HBV.

\section{Seafood consumption}

The GM seafood intake in our eight-year sample of reproductive-age women was 3.56 (95\% CI 3.48, 3.65) servings over the month prior to the NHANES interview. The six species most commonly consumed (the greatest number of servings by the largest share of the population) were, in order: shrimp, tuna (all types combined), salmon, crab, catfish, and breaded fish (assumed to be mainly pollock). These species represented $55 \%$ of total seafood intake. With the exception of tuna, average mercury tissue concentrations of these species do not generally exceed $0.1 \mathrm{ppm}$ in the US, and are not cautioned against in the national commercial seafood advisory to pregnant and reproductive-age women [39]. Remaining seafood intake was comprised of smaller numbers of women consuming fewer servings spread across 25 other species. The highest-mercury species (e. g., swordfish) were consumed relatively rarely, by few women. Each serving of seafood was associated with an increase in GM TBHg of $6 \%$ for the whole sample, an increase of $10 \%(\mathrm{p}<0.001)$ when considering women with HBV, and a decrease of $6 \%(\mathrm{p}=0.28)$ for those with $\mathrm{HCV}$ (results not shown).

\section{Ratios of blood mercury concentration by hepatitis status HAV Model A}

In regression analysis we found no significant association between HAV-positive status and GM TBHg concentrations (Table 4). This did not change after adjusting for estimated $\mathrm{MeHg}$ intake, household income, education attainment, ethnicity, BMI, alcohol intake, age, country of birth, and $\mathrm{HBV}$ and $\mathrm{HCV}$ status (GM TBHg ratio $1.02,95 \%$ CI 0.92, $1.14 \mathrm{p}=0.67$ ).

\section{HBV Model}

We found a statistically-significant positive association between being in the current HBV group and GM TBHg concentration (Table 4). The association remained after adjusting for estimated MeHg intake, household income, education attainment, ethnicity, country of birth, age, BMI, alcohol intake, and HIV status (GM TBHg ratio $1.52,95 \%$ CI 1.13, 2.05, $\mathrm{p}<0.01)$. The interaction term between seafood intake and chronic hepatitis was statistically significant $(\mathrm{p}<0.01)$. Regression results differed for the two sub-groups with current infection: For the active infection group the positive association after adjustment was stronger $(1.99,95 \% \mathrm{CI} 0.94,4.22, \mathrm{p}=0.07$; $\mathrm{n}=11)$ than for the inactive carrier group $(1.40,95 \% \mathrm{CI}$ $1.06,1.88, \mathrm{p}=0.02 ; \mathrm{n}=29)$. The association with having 
Table 2 Total blood mercury concentrations $(\mu \mathrm{g} / \mathrm{L})$ in study participants by selected covariates

\begin{tabular}{|c|c|c|c|c|c|c|c|c|}
\hline & $\mathbf{n}={ }^{1}$ & GM & $95 \% \mathrm{Cl}$ & $5^{\text {th }} \mathrm{P}$ & $25^{\text {th }} \mathrm{P}$ & $50^{\text {th }} \mathrm{P}$ & $75^{\text {th }} \mathrm{P}$ & $95^{\text {th }} \mathrm{P}$ \\
\hline Total & 5,189 & 1.02 & $(0.97,1.08)$ & 0.20 & 0.58 & 1.00 & 1.87 & 4.82 \\
\hline \multicolumn{9}{|l|}{ Age (yrs) } \\
\hline$-16-19$ & 1,103 & 0.74 & $(0.67,0.82)$ & 0.20 & 0.40 & 0.77 & 1.40 & 3.10 \\
\hline$-20-29$ & 1,404 & 0.88 & $(0.81,0.94)$ & 0.20 & 0.50 & 0.88 & 1.66 & 3.70 \\
\hline$-30-39$ & 1,358 & 1.13 & $(1.02,1.24)$ & 0.20 & 0.60 & 1.10 & 2.20 & 5.80 \\
\hline$-40-49$ & 1,324 & 1.14 & $(1.07,1.22)$ & 0.28 & 0.70 & 1.10 & 1.90 & 5.00 \\
\hline \multicolumn{9}{|l|}{ Ethnicity } \\
\hline - White & 2,100 & 1.00 & $(0.92,1.07)$ & 0.20 & 0.53 & 1.00 & 1.85 & 4.89 \\
\hline - Mexican American & 1,248 & 0.77 & $(0.71,0.84)$ & 0.20 & 0.49 & 0.80 & 1.30 & 2.91 \\
\hline - Other Hispanic & 328 & 1.04 & $(0.84,1.29)$ & 0.20 & 0.66 & 1.09 & 1.90 & 3.59 \\
\hline - Black & 1,285 & 1.08 & $(0.99,1.17)$ & 0.30 & 0.63 & 1.04 & 1.75 & 4.10 \\
\hline - Other & 228 & 1.90 & $(1.62,2.24)$ & 0.40 & 0.90 & 2.03 & 3.60 & 8.50 \\
\hline \multicolumn{9}{|l|}{ Country born } \\
\hline- US & 4,008 & 0.98 & $(0.92,1.04)$ & 0.20 & 0.54 & 0.95 & 1.70 & 4.45 \\
\hline - Foreign & 1,180 & 1.28 & $(1.15,1.42)$ & 0.28 & 0.70 & 1.25 & 2.49 & 6.52 \\
\hline \multicolumn{9}{|l|}{ Household income (/yr) } \\
\hline$-<\$ 45,000$ & 2,580 & 0.86 & $(0.80,0.92)$ & 0.20 & 0.50 & 0.82 & 1.54 & 3.64 \\
\hline$-\$ 45,000-\$ 75,000$ & 1,070 & 1.03 & $(0.95,1.11)$ & 0.23 & 0.60 & 1.00 & 1.80 & 4.90 \\
\hline - > \$75,000 & 1,217 & 1.29 & $(1.19,1.30)$ & 0.30 & 0.60 & 1.27 & 2.30 & 5.82 \\
\hline \multicolumn{9}{|l|}{ Education } \\
\hline - <HS diploma & 1,695 & 0.76 & $(0.70,0.83)$ & 0.20 & 0.40 & 0.75 & 1.39 & 3.30 \\
\hline - HS diploma & 1,052 & 0.93 & $(0.85,1.00)$ & 0.20 & 0.50 & 0.90 & 1.60 & 4.01 \\
\hline - BA degree & 1,496 & 1.02 & $(0.94,1.11)$ & 0.20 & 0.60 & 1.00 & 1.80 & 4.10 \\
\hline ->BA degree & 944 & 1.37 & $(1.26,1.49)$ & 0.30 & 0.72 & 1.35 & 2.62 & 6.40 \\
\hline \multicolumn{9}{|l|}{ BMI $\left(\mathrm{kg} / \mathrm{m}^{2}\right)$} \\
\hline$-<30$ & 3,920 & 1.10 & $(1.03,1.17)$ & 0.20 & 0.60 & 1.10 & 2.00 & 5.16 \\
\hline$->=30$ & 1,706 & 0.89 & $(0.83,0.95)$ & 0.20 & 0.50 & 0.86 & 1.50 & 4.00 \\
\hline \multicolumn{9}{|l|}{ Alcohol (g/day) } \\
\hline$-<10$ & 4,500 & 0.97 & $(0.91,1.03)$ & 0.20 & 0.53 & 0.93 & 1.71 & 4.50 \\
\hline$->=10$ & 683 & 1.29 & $(1.18,1.42)$ & 0.30 & 0.71 & 1.29 & 2.31 & 5.58 \\
\hline \multicolumn{9}{|l|}{ Seafood (/mo.) } \\
\hline - 1-4 servings & 4,422 & 0.93 & $(0.88,0.99)$ & 0.20 & 0.52 & 0.90 & 1.62 & 4.17 \\
\hline - 5-8 servings & 458 & 1.72 & $(1.55,1.91)$ & 0.41 & 0.90 & 1.76 & 3.01 & 7.52 \\
\hline$->/=9$ servings & 198 & 2.08 & $(1.81,2.39)$ & 0.65 & 1.14 & 1.92 & 3.70 & 10.60 \\
\hline \multicolumn{9}{|l|}{ Hepatitis A } \\
\hline - No infection or immunization & 2,669 & 1.03 & $(0.99,1.07)$ & 0.20 & 0.60 & 1.00 & 1.90 & 4.90 \\
\hline - Infection or immunization & 1,484 & 1.04 & $(0.99,1.05)$ & 0.23 & 0.60 & 1.00 & 1.90 & 5.10 \\
\hline \multicolumn{9}{|l|}{ Hepatitis B } \\
\hline - No infection or immunization & 4,957 & 1.01 & $(0.96,1.07)$ & 0.20 & 0.57 & 1.00 & 1.81 & 4.70 \\
\hline - Past or current infection ${ }^{2}$ & 185 & 1.39 & $(1.16,1.65)$ & 0.20 & 0.70 & 1.30 & 3.80 & 6.90 \\
\hline - Immunization & 1,673 & 1.08 & $(1.03,1.13)$ & 0.20 & 0.68 & 1.07 & 1.98 & 4.90 \\
\hline \multicolumn{9}{|l|}{ Hepatitis C } \\
\hline - No infection & 5,055 & 1.03 & $(0.97,1.09)$ & 0.20 & 0.59 & 1.00 & 1.89 & 4.80 \\
\hline - Past or current infection & 70 & 0.74 & $(0.55,1.01)$ & 0.20 & 0.40 & 0.85 & 1.60 & 3.40 \\
\hline
\end{tabular}

\footnotetext{
${ }^{1}$ Includes all models; sample sizes do not always sum due to missing values. HAV analysis 2001-2006 only.
}

${ }^{2}$ Current HBV and recovered HBV groups combined. 
Table 3 Characteristics of study participants by hepatitis serological marker status

\begin{tabular}{|c|c|c|c|c|c|c|}
\hline & \multirow{2}{*}{\multicolumn{2}{|c|}{$\begin{array}{l}\text { Hepatitis A } \\
\text { Anti-HAVT }^{1}\end{array}$}} & \multirow{2}{*}{\multicolumn{2}{|c|}{$\begin{array}{l}\text { Hepatitis B } \\
\text { Anti-HBc }^{2}\end{array}$}} & \multirow{2}{*}{\multicolumn{2}{|c|}{$\begin{array}{r}\text { Hepatitis C } \\
\text { Anti-HCV }^{3}\end{array}$}} \\
\hline & & & & & & \\
\hline & Positive & Negative & Positive & Negative & Positive & Negative \\
\hline$N=$ & 1,466 & 2,638 & 185 & 4,903 & 70 & 5,001 \\
\hline Age (yrs) & 30.5 & 29.0 & 36.6 & 30.5 & 40.9 & 30.5 \\
\hline \multicolumn{7}{|l|}{ Ethnicity (\%) } \\
\hline - White & $22 \%$ & $51 \%$ & $22 \%$ & $41 \%$ & $51 \%$ & $40 \%$ \\
\hline - Mexican American & $49 \%$ & $12 \%$ & $15 \%$ & $31 \%$ & $13 \%$ & $31 \%$ \\
\hline - Other Hispanic & $6 \%$ & $4 \%$ & & & & \\
\hline - Black & $17 \%$ & $30 \%$ & $48 \%$ & $24 \%$ & $30 \%$ & $25 \%$ \\
\hline - Other & $5 \%$ & $4 \%$ & $15 \%$ & $4 \%$ & $7 \%$ & $4 \%$ \\
\hline Country born (\% US) & $51 \%$ & $94 \%$ & $61 \%$ & $76 \%$ & $96 \%$ & $78 \%$ \\
\hline \multicolumn{7}{|l|}{ Household income (\%) } \\
\hline$-<\$ 45,000 / y r$ & $63 \%$ & $48 \%$ & $72 \%$ & $52 \%$ & $85 \%$ & $52 \%$ \\
\hline - $\$ 45,000-\$ 75,000 / y r$ & $20 \%$ & $23 \%$ & $17 \%$ & $22 \%$ & $11 \%$ & $22 \%$ \\
\hline - > \$75,000/yr & $17 \%$ & $29 \%$ & $12 \%$ & $26 \%$ & $5 \%$ & $26 \%$ \\
\hline \multicolumn{7}{|l|}{ Education (\%) } \\
\hline - < HS diploma & $45 \%$ & $28 \%$ & $29 \%$ & $33 \%$ & $38 \%$ & $33 \%$ \\
\hline - HS diploma & $18 \%$ & $21 \%$ & $29 \%$ & $20 \%$ & $32 \%$ & $20 \%$ \\
\hline - BA degree & $23 \%$ & $30 \%$ & $27 \%$ & $29 \%$ & $25 \%$ & $29 \%$ \\
\hline -> BA degree & $13 \%$ & $21 \%$ & $16 \%$ & $18 \%$ & $4 \%$ & $19 \%$ \\
\hline BMI $(\%<30)$ & $68 \%$ & $67 \%$ & $64 \%$ & $67 \%$ & $66 \%$ & $67 \%$ \\
\hline Alcohol $(\%<10 \mathrm{~g} / \mathrm{d})$ & $89 \%$ & $87 \%$ & $84 \%$ & $87 \%$ & $70 \%$ & $87 \%$ \\
\hline Seafood (GM servings) & 3.5 & 3.6 & 4.0 & 3.5 & 3.2 & 3.6 \\
\hline Anti-HAVT + (\%) & - & - & $53 \%$ & - & $48 \%$ & - \\
\hline HBV co-infected (\%) & $6 \%$ & - & - & - & $30 \%$ & - \\
\hline HCV co-infected (\%) & $2 \%$ & - & $11 \%$ & - & - & - \\
\hline
\end{tabular}

recovered from HBV was modestly positive, though not statistically significant $(1.14,95 \%$ CI $0.93,1.39, \mathrm{p}=0.21)$. We found a weak, non-significant positive association with $\mathrm{HBV}$ vaccination $(1.07,95 \%$ CI $0.98,1.16, \mathrm{p}=0.11)$ after adjusting for the covariates described.

\section{HCV Model}

We found a modest negative association between GM TBHg concentration and HCV (Table 4). The association remained after adjusting for estimated $\mathrm{MeHg}$ intake, household income, education attainment, ethnicity, country of birth, age, BMI, alcohol intake and HBV status, and reached borderline statistical significance (GM $\mathrm{TBHg}$ ratio $0.72,95 \%$ CI $0.51,0.99, \mathrm{p}=0.05$ ).

\section{Discussion}

In this study of a large representative sample of reproductive-age seafood-consuming American women we found those with markers of current chronic HBV infection had 1.52 times the adjusted blood mercury concentration of those never having had contact with the HBV virus or vaccine. The finding was statistically significant thus unlikely due to chance alone. Among those with current disease, the GM TBHg ratio was 1.40 for inactive HBV carriers and 1.99 for those with active $\mathrm{HBV}$, the most severe form of disease in this sample. Women with recovered HBV, the mildest HBV disease state we examined, had 1.14 times the adjusted GM $\mathrm{TBHg}$ concentration of the never-infected or vaccinated. Although some strata were small, these results are suggestive of an increasing strength of association with increasing severity of disease which adds weight to our finding. We found no significant association between GM TBHg concentrations and either having (or being vaccinated for) acute-only HAV or having been vaccinated for HBV, situations normally without longer-term risk of damage to the liver or gallbladder. These findings are consistent with our proposed explanation that damage to hepatobiliary elimination structures induced by chronic viral hepatitis could interfere with MeHg's EH 
Table 4 Ratio of geometric mean total blood mercury (GM TBHg) concentrations comparing study participants by hepatitis group

\begin{tabular}{|c|c|c|c|c|c|c|c|}
\hline \multirow[b]{2}{*}{ Model/group } & \multirow[b]{2}{*}{$\mathbf{N}=$} & \multicolumn{3}{|c|}{ Unadjusted } & \multicolumn{3}{|c|}{ Adjusted } \\
\hline & & GM TBHg Ratio $^{1}$ & 95\% Conf. Int. & p- value ${ }^{2}$ & GM TBHg Ratio $^{1}$ & 95\% Conf. Int. & $p$ - value ${ }^{2}$ \\
\hline \multicolumn{8}{|c|}{ Hepatitis A Model $^{3}$ (total $n=4,104$ ) } \\
\hline - Infection or immunization & 1,466 & 1.01 & $0.92,1.11$ & 0.786 & 1.02 & $0.92,1.14$ & 0.674 \\
\hline \multicolumn{8}{|c|}{ Hepatitis B Model ${ }^{4}$ (total $n=5,088$ ) } \\
\hline - Current infection & 40 & 1.84 & $1.37,2.46$ & 0.000 & 1.52 & $1.13,2.05$ & 0.007 \\
\hline Active & 11 & 4.17 & $1.90,8.93$ & 0.000 & 1.99 & $0.94,4.22$ & 0.072 \\
\hline Inactive & 29 & 1.43 & $1.08,1.90$ & 0.014 & 1.40 & $1.06,1.88$ & 0.020 \\
\hline - Recovered infection & 145 & 1.31 & $1.07,1.59$ & 0.009 & 1.14 & $0.93,1.39$ & 0.205 \\
\hline - Immunized & 1,520 & 1.04 & $0.96,1.14$ & 0.270 & 1.07 & $0.98,1.16$ & 0.111 \\
\hline \multicolumn{8}{|c|}{ Hepatitis C Model ${ }^{5}$ (total $\left.n=5,071\right)$} \\
\hline - Infection & 70 & 0.72 & $0.53,0.98$ & 0.039 & 0.72 & $0.51,0.99$ & 0.049 \\
\hline
\end{tabular}

cycle, lead to attenuated MeHg elimination, and be reflected in higher concentrations of circulating $\mathrm{TBHg}$.

The modest negative association $(0.72, \mathrm{p}=0.05)$ we observed between HCV-positive status and GM TBHg concentration was inconsistent with our hypothesis. However, a finding of different outcomes for HBV and $\mathrm{HCV}$ is plausible scientifically. While we hypothesized both $\mathrm{HBV}$ and $\mathrm{HCV}$ would lead to reduced $\mathrm{MeHg}$ elimination into bile, the $\mathrm{EH}$ cycle can also be accelerated by liver and gallbladder dysfunction reducing uptake into hepatocytes or altering metabolism [18]. For example, $\mathrm{MeHg}$ has been found to be eliminated more quickly in laboratory animals with ligated cystic ducts, in which reabsorption to the gallbladder is prevented [16]. Cirrhosis - a more frequent longer-term outcome of HCV than of HBV - has been shown to lead to reduced hepatic uptake due to lower perfusion of cells [18]. Presence of gallstones, associated in the epidemiological literature with $\mathrm{HCV}$ but not HBV $[30,31,44,45]$, has also been associated with faster gallbladder emptying [46]. In a recent study, flavonoligands of silymarin - which are eliminated through an EH cycle in circumstances of normal liver health - were found not to undergo EH cycling in $\mathrm{HCV}$ patients, whereas substantial $\mathrm{EH}$ cycling was found in non-alcoholic fatty liver disease patients [47]. The authors hypothesized HCV-specific changes in hepatobiliary function led to the observed absence of $\mathrm{EH}$ cycling. Our $\mathrm{HCV}$ findings of lower adjusted $\mathrm{MeHg}$ levels among $\mathrm{HCV}$-infected women appear consistent with this research.

To further assess possible reasons for the differing findings for $\mathrm{HBV}$ and $\mathrm{HCV}$ we also examined six clinical markers of liver function analyzed in the laboratory component of NHANES: alanine transaminase (ALT), aspartate transaminase (ALT), alkaline phosphatase (ALP), gamma glutamyl transpeptidase (GGT), bilirubin and albumin. In our sample, women with current HBV had statistically significant higher ALP and lower albumin levels than those without HBV (Table 5). ALP is observed to be higher in cholestatic conditions where normal bile flow is blocked or interrupted [48]. Those with HCV had statistically significant higher transaminase, ALP and GGT levels. Lower hepatic GGT (which may lead to higher serum GGT) has been associated with faster $\mathrm{MeHg}$ elimination through the $\mathrm{EH}$ cycle in laboratory animals [16]. In our sample, the magnitude of

Table 5 Liver enzymes (mean) measured in blood, by hepatitis group

\begin{tabular}{|c|c|c|c|c|c|c|}
\hline & ALT & AST & ALP & GGT & Bilirubin & Albumin \\
\hline Units & $\overline{I U / L}$ & $\overline{\mathrm{IU} / \mathrm{L}}$ & $\overline{\mathrm{IU} / \mathrm{L}}$ & $\overline{\mathrm{IU} / \mathrm{L}}$ & $\overline{\mathrm{mg} / \mathrm{dL}}$ & $\mathrm{g} / \mathrm{dL}$ \\
\hline \multicolumn{7}{|l|}{ Hepatitis A } \\
\hline No infection or immunization & 19.3 & 21.4 & 65.9 & 18.5 & 0.65 & 4.07 \\
\hline Infection or immunization & 20.8 & 21.9 & 75.7 & 18.7 & 0.63 & 4.07 \\
\hline \multicolumn{7}{|l|}{ Hepatitis B } \\
\hline No infection or immunization & 20.2 & 22.0 & 66.7 & 19.4 & 0.64 & 4.08 \\
\hline Current infection & 24.2 & 24.2 & 72.4 & 24.1 & 0.62 & 3.92 \\
\hline - Active & 22.3 & 24.5 & 88.0 & 21.0 & 0.65 & 3.71 \\
\hline - Inactive & 24.8 & 24.0 & 66.6 & 25.2 & 0.61 & 3.99 \\
\hline Recovered infection & 20.2 & 22.1 & 65.3 & 21.0 & 0.61 & 4.02 \\
\hline Immunization & 18.9 & 21.6 & 65.3 & 16.4 & 0.67 & 4.14 \\
\hline \multicolumn{7}{|l|}{ Hepatitis C } \\
\hline No infection & 20.0 & 21.7 & 66.9 & 19.1 & 0.64 & 4.08 \\
\hline Past or present infection & 39.2 & 37.6 & 70.3 & 48.9 & 0.61 & 3.98 \\
\hline
\end{tabular}


the negative association between GM TBHg concentration and presence of anti-HCV was strongest in those with the highest serum GGT levels. These liver marker data are suggestive of possible differences in biliary elimination patterns between the HBV- and $\mathrm{HCV}$-infected in our sample. Of additional relevance to our findings, alcohol intake has also been associated with lower blood $\mathrm{Hg}$ concentrations $[15,49]$. Women positive for $\mathrm{HCV}$ in our sample had higher than average alcohol intake (whereas those positive for HBV did not), suggesting a further possible factor in the negative association observed.

This study had several limitations. Its cross-sectional design precludes inferences regarding causality. Mercury is known to be hepatotoxic in high doses [1], and this could explain the positive association found with HBV infection. Studies in rats and seals have found positive associations between $\mathrm{Hg}$ tissue concentrations and levels of some liver enzymes, and have elucidated oxidative stress and other mechanisms of mercury's hepatotoxicity [20,50]. In humans, clinical case reports have found acute auto-immune hepatitis in association with inorganic $\mathrm{Hg}$ overdose [51,52]. With regard to $\mathrm{MeHg}$, elevated standard mortality ratios were found for liver conditions among male Minamata disease survivors in some studies [53,54], but not in others [55]. A positive association between ALT levels and TBHg was observed in a study of US adults, although causality could not be determined due to the cross-sectional design [56]. As noted by several researchers, despite MeHg's extensive EH cycling and presence in the liver, the scientific literature on its hepatotoxicity is limited $[20,50]$.

While we believe viral hepatitis-induced gallbladder damage and ensuing alteration of MeHg's $\mathrm{EH}$ cycle is the more plausible explanation for both our $\mathrm{HBV}$ and $\mathrm{HCV}$ findings, other factors we were unable to test may contribute to explaining observed associations. For example, MeHg is eliminated from the body as GSH-conjugates, and GSH depletion is known to reduce the pace of $\mathrm{MeHg}$ elimination [15]. Several genetic polymorphisms for production of glutathione-s-transferase (GST) have been associated with $\mathrm{MeHg}$ retention [7]. NHANES data for 2001-2008 did not provide data on serum levels of GSH or GST genetic variants, therefore these variables could not be tested in the analysis. It is possible that mercury intake from other sources (e.g., elemental mercury from dental amalgams) may confound our analysis, since other $\mathrm{Hg}$ forms can be reflected in $\mathrm{TBHg}$ measures [15]. Differences in $\mathrm{MeHg}$ toxicokinetics below steady state intake can be important [13] and may play a role in our findings in this US population with comparatively low $\mathrm{MeHg}$ exposures. Data were not available to allow us to control for other forms of $\mathrm{Hg}$ intake, however there is no a priori evidence that women with chronic hepatitis would have higher exposure to other $\mathrm{Hg}$ sources than those without. Additional toxicokinetic factors may be involved. For example, presence of chronic HBV may trigger release of stored $\mathrm{MeHg}$ in the liver thereby increasing its circulation in blood, as has been hypothesized for tea consumption [57].

It is also possible that Hg's immunotoxic effects could make exposed individuals vulnerable to viral hepatitis. Animal studies have found chronic exposure to low doses of $\mathrm{MeHg}$ initially depress immune function then stimulate an auto-immune response [58]. Studies in a human population in Brazil's Amazon Basin found that $\mathrm{Hg}$ immunotoxicity may be a factor in malaria infection [59]. Neither HBV nor HCV is cytotoxic; liver damage is thought to occur due to the response mounted by the immune system $[24,60]$. The relationship between $\mathrm{Hg}$ immunotoxicity and HBV in particular may warrant further study.

Because of the potential for HBV reactivation, and the blurred line between low-grade infection and recovering disease [24], the inactive HBV carrier category in this analysis may include some women with active infection. In addition, HCV-RNA - a better indicator of chronic $\mathrm{HCV}$ - was available for only a portion of our sample, resulting in strata size too small for analysis. However, we believe any possible disease misclassification is likely to have been minor, and would not have had a significant effect on results.

The fact that $\mathrm{MeHg}$ intake was estimated based on seafood frequency and species data from a self-report questionnaire is a drawback of study design. This limitation is mitigated to some extent by the careful NHANES survey design and implementation and use of quality control measures described, and by the finding that seafood is among foods least prone to recall bias [34]. The use of $\mathrm{TBHg}$, a biomarker reflective of recent $\mathrm{MeHg}$ exposure [15], is consistent with the one-month seafood intake data available in NHANES. However, MeHg's half-life is on average closer to two months. To address seafood data shortcomings, we performed several sensitivity analyses. In light of higher reported seafood and estimated $\mathrm{MeHg}$ intake in the current HBV group than sample average, we ran our model excluding the three observations in this group with highest estimated $\mathrm{MeHg}$ intake. The current HBV group's estimated $\mathrm{MeHg}$ intake fell to near sample average and the adjusted GM TBHg ratio was $1.40(95 \% \mathrm{CI} 1.07,1.83, \mathrm{p}=0.02)$, broadly consistent with our main HBV model findings (results not shown). We also evaluated intake of the most commonly-consumed seafood species and found patterns across disease categories were not markedly different. 


\section{Conclusions}

This study found that TBHg levels varied by hepatitis status among American reproductive-age seafood-consuming women, and the observed associations remained after adjusting for estimated $\mathrm{MeHg}$ intake from seafood consumption and other predictors. While limited by the constraints of a cross-sectional design, these results raise the possibility that chronic viral liver disease may alter the pace of $\mathrm{MeHg}$ hepatobiliary elimination in reproductiveage women - and therefore also affect the risk of neurotoxicity to the developing fetus. The finding that seafood-consuming reproductive-age women with chronic hepatitis B had 1.52 times the blood mercury concentrations as women having had no contact with the virus is of public health relevance. In particular, it suggests offspring of HBV-positive high seafood-consuming women may be at higher risk of verbal, spatial and finemotor skill delays associated with MeHg-induced developmental neurotoxicity. The implications may be particularly relevant in populations where chronic HBV prevalence and seafood intake are both high (such as US women of Asian and Pacific Islands ethnicity [24,61]).

This representative US sample was ethnically and socially heterogenous, therefore it is reasonable to consider possible implications of generalizing the findings internationally. Higher TBHg levels are observed in a number of regions - e.g., Southeast Asia, the Amazon Basin, and the Arctic [3] - where HBV is also endemic [62,63]. Further study of the impact of liver disease on $\mathrm{MeHg}$ elimination is warranted, in both animals and humans. Possible policy implications include enhancing riskcommunication through targeting of commercial seafood advisories, adding mercury testing to existing HBV screening programs for reproductive-age women, and enhanced high-risk population surveillance.

\section{Abbreviations}

Anti-HAVT: Total hepatitis A antibody; Anti-HBc: Hepatitis B core antibody; Anti-HBs: Hepatitis B surface antibody; Anti-HCV: Hepatitis C antibody; EH: Enterohepatic; ELISA: Enzyme-linked immunosorbent assay; GM: Geometric mean; HBsAg: Hepatitis B surface antigen; Hg: Mercury; MeHg: Methylmercury; TBHg: Total blood mercury.

\section{Competing interests}

All authors declare they have no completing financial or non-financial interests.

\section{Authors' contributions}

MAF participated in the design of the study, statistical analysis and interpretation of findings. TAB, PNB and ANA participated in the design of the study and interpretation of findings. JM participated in the statistical analysis. MCS conceived of the study, participated in study design, statistical analysis and interpretation of findings and drafted the manuscript. All authors read and approved the final manuscript.

\section{Acknowledgements}

This paper was prepared as part of a PhD dissertation conducted at Johns Hopkins Bloomberg School of Public Health. The content of this paper is solely the responsibility of the authors. The authors wish to acknowledge the peer reviewers, and Mark Thomas for helpful comments.

\section{Author details}

'Department of Health Policy and Management, Johns Hopkins Bloomberg School of Public Health, Baltimore, MD, USA. ${ }^{2}$ Department of Environmenta Health Sciences, Johns Hopkins Bloomberg School of Public Health, Baltimore, MD, USA. ${ }^{3}$ Department of Statistics, Johns Hopkins Bloomberg School of Public Health, Baltimore, MD, USA.

Received: 30 April 2012 Accepted: 23 August 2012

Published: 12 September 2012

\section{References}

1. International Program for Chemical Safety: Environmental health criteria document 101: Mmethylmercury. Geneva: World Health Organisation; 1990.

2. National Research Council: Toxicological effects of methylmercury. Committee on the Toxicological Effects of Methylmercury, Board on Environmental Studies and Toxicology. Washington DC: National Academies Press; 2000.

3. Sheehan MC: Risk of developmental neurotoxicity due to methylmercury in seafood: examining global exposures, susceptibility and policy. PhD thesis. Johns Hopkins Bloomberg: School of Public Health, Health Policy and Management Department; 2011.

4. Hattis D, Banati P, Goble R: Distribution of individual susceptibility among humans for toxic effect: how much protection does the traditional tenfold factor provide for what fraction of which kinds of chemicals and effects? Ann NY Acad Sci 1999, 895:286-316.

5. National Research Council: Science and decisions: advancing risk assessment. Committee on Improving Risk Analysis Approaches Used by the US EPA, Board on Environmental Studies and Toxicology. Washington DC: National Academies Press; 2009.

6. Nielsen JB, Andersen O: Elimination of recently absorbed methyl mercury depends on age and gender. Pharmacol Toxicol 1996, 79:60-64.

7. Custodio H, Broberg K, Wennberg M, Jansson J, Vessby B, Halmans G, Stegmayr B, Skerfving S: Polymorphisms in glutathione-related genes affect methylmercury retention. Arch Environ Health 2004, 59:588-595.

8. Choi AL, Butz-Jorgensen E, Jorgensen PJ, Steuerwald U, Debes F, Weihe P, Grandjean P: Selenium as a potential protective factor against mercury developmental toxicity. Environ Res 2008, 107:45-52.

9. Passos CJ, Da Silva DS, Lemire M, Fillion M, Guimaraes JR, Lucotte M, Mergler D: Daily mercury intake in fish-eating populations in the Brazilian Amazon. J Expo Sci Environ Epidemiol 2008, 18:76-87.

10. Huang L-S, Myers GJ, Davidson PW, Cox C, Xiao F, Thurston SW, Cernichiari E, Shamlaye EF, Sloane-Reeves J, Georger L, Clarkson TW: Is susceptibility to prenatal methylmercury exposure from fish consumption nonhomogenous? Tree-structured analysis for the Seychelles Child Development Study. Neurotoxicol 2007, 28:1237-1244.

11. Castoldi AF, Johansson C, Onishchenko N, Coccini T, Roda E, Vahter M: Human developmental neurotoxicity of methylmercury: impact of variables and risk modifiers. Reg Toxicol Pharmacol 2008, 51:201-214.

12. Rice D: Overview of modifiers of methylmercury neurotoxicity: chemicals, nutrients and the social environment. NeuroToxicity 2008, 29:761-766.

13. Bartell SM, Ponce RA, Sanga RN, Faustman EM: Human variability in mercury toxicokinetics and steady state biomarker ratios. Environ Res 2000, SA84:127-132.

14. Agency for Toxic Substances and Disease Regristry: Toxicological profile for mercury. Washington DC: Department of Health and Human Resources; 1999.

15. Clarkson TW, Magos L: The toxicology of mercury and its chemical compounds. Crit Rev Toxicol 2006, 36:609-662

16. Dutczak WJ, Clarkson TW, Ballatori N: Biliary-hepatic recycling of a xenobiotic: gallbladder absorption of methylmercury. Am J Physiol 1991, 260:G873-G880.

17. Environmental Protection Agency: Methylmercury - Integrated Risk Information System. 2001. http://www.epa.gov/iris/subst/0073.htm.

18. Roberts MS, Rasmussen B, Burczynski FJ, Weiss M: Enterohepatic circulation: physiological, pharmacokinetic and clinical implications. Clin Pharmacokinet 2002, 41:751-790.

19. Hofman AF: Biliary secretion and excretion in health and disease: current concepts. Ann Hepatol 2007, 6:15-27.

20. Reus IS, Bando I, Andres D, Cascales M: Relationship between expression of HSP70 and metallothionein and oxidative stress during mercury chloride induced acute liver injury in rats. J Biochem Mol Toxicol 2003, 17:161-168 
21. Ballatori N, Wang W, Lieberman MW: Accelerated methylmercury elimination in gamma-glutamyl transpeptidase-deficient mice. Am J Pathol 1998, 152:1049-1055.

22. Jansen PL: Liver disease in the elderly. Best Pract Res Clin Gastroenterol 2002, 16:149-158.

23. Ginsberg G, Hattis D, Russ A, Sonawane B: Pharmacokinetic and pharmacodynamic factors that can affect sensitivity to neurotoxic sequelae in elderly individuals. Environ Health Perspect 2005, 113:12431249.

24. Institute of Medicine: Hepatitis and liver cancer: a national strategy for prevention and control of hepatitis B and C. Washington DC: National Academies Press; 2010

25. National Institutes of Diabetes and Digestive and Kidney Diseases: Action plan for liver disease research. Washington DC: US Department of Health and Human Services; 2009.

26. Fiel MI: Pathology of chronic hepatitis B and chronic hepatitis C. Clin Liver Dis 2010, 4:555-575.

27. Arns PA, Adedoyin A, DiBisceglie AM, Waggoner JG, Hoofnagle JH, Wilkinson GR, Branch RA: Mephenytoin disposition and serum bile acids as indices of hepatic function in chronic viral hepatitis. Clin Pharmacol Ther 1997, 62:527-537.

28. Wald O, Pappo O, Safadi R, Dagan-Berger M, Beider K, Wald H, Franitza S, Weiss I, Avniel S, Boaz P, Hanna J, Zamir G, Eld A, Mandelboim O, Spengler $U$, Galun E, Peled A: Involvement of the CXCL12/CXCR4 pathway in the advanced liver disease that is associated with hepatitis $C$ virus or hepatitis B virus. Eur J Immunol 2004, 34:1164-1174.

29. Maudgal DP, Wansbrough-Jones MH, Joseph AE: Gallbladder abnormalities in acute infectious hepatitis: a prospective study. Dig Dis Sci 1984, 29:257-260

30. Bini EJ, McGready J: Prevalence of gallbladder disease among persons with hepatitis C virus infection in the United States. Hepatology 2005, 41:1029-1036.

31. Fwu CW, Chien YC, Nelson KE, Kirk GD, You SL, Kuo HS, Feinleib M, Chen CJ: Mortality after chronic hepatitis B virus infection: a linkage study involving 2 million parous women from Taiwan. J Infect Dis 2010, 1 (201):1016-1023.

32. Tao LY, He XD, Qu Q, Cai L, Liu W, Zhou L, Zhang SM: Risk factors for intrahepatic and extrahepatic cholangiocarcinoma: a case-control study in China. Liver Int 2010, 30:215-221.

33. Berglund M, Lind B, Bjornberg KA, Palm B, Einarsson O, Vahter M: Interindividual variations of human mercury exposure biomarkers: a cross sectional assessment. Environ Health 2005, 4:20.

34. Mahaffey KR, Clickner RP, Bodurow CC: Blood organic mercury and dietary mercury intake: National Health and Nutrition Examination Survey 19992000. Environ Health Perspect 2004, 2:562-570

35. Centers for Disease Control and Prevention: Chronic hepatitis B virus: 2011 case definition. CSTE Position Statement Number 10-ID10. http://www.cdc. gov/osels/ph_surveillance/nndss/casedef/hepatitisbcurrent.htm.

36. Centers for Disease Control and Prevention: Chronic hepatitis C virus: 2010 case definition. CSTE Position Statement Number 09-ID-41. http://www.cdc gov/osels/ph_surveillance/nndss/casedef/hepatitisc2010.htm.

37. Centers for Disease Control and Prevention: Interpretation of hepatitis B serological test results. Atlanta: Department of Health and Human Services; http://www.cdc.gov/hepatitis/HBV/PDFs/SerologicChartv8.pdf.

38. Food and Drug Administration: Mercury concentrations in fish and shellfish. Washington DC: 2011. http://www.fda.gov/Food/FoodSafety/ProductSpecificInformation/Seafood/FoodbornePathogensContaminants/ Methylmercury/ucm191007.htm.

39. Food and Drug Administration: What You Need to Know About Mercury in Fish and Shellfish. Washington DC: 2004. http://www.fda.gov/food/ foodsafety/product-specificinformation/seafood/ foodbornepathogenscontaminants/methylmercury/ucm115662.htm.

40. Mahaffey KR: Mercury exposure: medical and public health issues. Trans Am Clin Climatol Assoc 2005, 116:27-53.

41. Mahaffey KR, Clickner RP, Jeffries RA: Methylmercury and omega-3 fatty acids: co-occurrence of dietary sources with emphasis on fish and shellfish. Environ Res 2008, 107:20-29.

42. Mahaffey KR, Clickner RP, Jeffries RA: Adult women's blood mercury concentrations vary regionally in the United States: association with patterns of fish consumption (NHANES 1999-2004). Environ Health Perspect 2009, 177:47-53.
43. Chen W, Krahn M: Review: ribavirin is not better than placebo in chronic hepatitis C infection. ACP J Club 2006, 145:47.

44. Stroffolini T, Sagnelli E, Mele A, Cottone C, Almasio PL: Italian Hospitals' Collaborating Group. HCV infection is a risk factor for gallstone disease in liver cirrhosis: an Italian epidemiological survey. J Viral Hepat 2007, 14:618-623.

45. Chang TS, Lo SK, Shyr HY, Fang JT, Lee WC, Tai DI, Sheen IS, Lin DY, Chu CM, Liaw YF: Hepatitis $C$ virus infection facilitates gallstone formation. J Gastroenterol Hepatol 2005, 20:1416-1421.

46. Maudgal DP, Kupfer RM, Zentler-Munro PL, Northfield TC: Postprandial gallbladder emptying in patients with gall stones. Br Med J 1980, 19:141-143.

47. Schrieber SJ, Hawke RL, Wen Z, Smith PC, Reddy KR, Wahed AS, Belle SH, Afdhal NH, Navarro VJ, Meyers CM, Doo E, Fried MW: Differences in the disposition of silymarin between patients with nonalcoholic fatty liver disease and chronic hepatitis C. Drug Metab Dispos 2011, 39:2182-2190.

48. Lee TH, Kim WR, Poterucha JJ: Evaluation of elevated liver enzymes. Clin Liver Dis 2012, 16:183-198.

49. Grandjean P, Weihe P, White RF, Debes F, Araki S, Yokoyama K, Murata K, Sorensen N, Dahl R, Jorgensen PJ: Cognitive deficit in 7-year old children with prenatal exposure to methylmercury. Neurotoxicol Teratolog 1997, 19:417-428

50. Ung CY, Lam SH, Hlaing MM, Winata CL, Korzh S, Mathavan S, Gong Z Mercury-induced hepatotoxicity in zebrafish: in vivo mechanistic insights from transcriptome analysis, phenotype anchoring and targeted gene expression validation. BMC Genomics 2010, 11:212

51. Girault $P-Y$, Rey $P$, Veran $Y$ : Hépatite aigue après application cutanée d'une pommade artisanale contenant du mercure. Gastroenterol Clin Biol 2008, 32:819-823.

52. Al-Sinani S, Al-Rawas A, Dhawan A: Mercury as a cause of fulminant hepatic failure in a child: case report and literature review. Clin Res Hepatol Gastroenterol 2011, 35:580-582.

53. Tamashiro $H$, Arakaki M, Akagi H, Futatsuka M, Roht LH: Mortality and survival for Minamata disease. Int J Epidemiol 1985, 14:582-588.

54. Kinjyo Y, Nakano A, Sakamoto M, Futatsuka M, Kato H: Clarification of mortality patterns among Minamata disease patients. Environ Sci 1991 $1: 73-88$.

55. Futatsuka M, Kitano T, Shono M, Nagano M, Wakamiya J, Miyamoto K, Ushijima K, Inaoka T, Fukuda Y, Nakagawa M, Arimura K, Osame M: Longterm follow-up study of health status in population living in methylmercury-polluted area. Environ Sci 2005, 12:239-282.

56. Cave M, Appana S, Patel M, Falkner KC, McClain CJ, Brock G: Polychlorinated biphenyls, lead, and mercury are associated with liver disease in American adults: NHANES 2003-2004. Environ Health Perspect 2010, 118:1735-1742.

57. Canuel R, de Grosbois BS, Lucotte M, Atikesse L, Larose C, Rheault I: New evidence on the effects of tea on mercury metabolism in humans. Arch Environ Occup Health 2006, 61:232-238.

58. Vas J, Monestier M: Review: immunology of mercury. Ann NY Academy of Sci 2008, 43:240-267

59. Silbergeld EK, Silva IA, Nyland JF: Mercury and autoimmunity: implications for occupational and environmental health. Toxicol Appl Pharmacol 2005, 207:282-292.

60. Maini MK, Bertoletti A: How can the cellular immune response control hepatitis B replication? J Viral Hepat 2000, 7:321-326.

61. Hightower JM, O'Hare A, Hernandez GT: Blood mercury reporting in NHANES: identifying Asian, Pacific Islander, Native American, and multiracial groups. Environ Health Perspect 2006, 114:173-175.

62. Merican I, Guan R, Amarapuka D, Alexander MJ, Chutaputti A, Chien RN, Hasnian SS, Leung N, Lesmana L, Phiet PH, Sjalfoellah Noer HM, Sollano J, Sun HS, Xu DZ: Special report: chronic hepatitis B virus infection in Asian countries. J Gastroenterol Hepatol 2000, 15:1356-1361.

63. Franco E, Bagnato B, Marino MG, Meleleo C, Serino L, Zaratti L: Hepatitis B: epidemiology and prevention in developing countries. World J Hepatol 2012, 4:74-80

doi:10.1186/1476-069X-11-62

Cite this article as: Sheehan et al: Association of markers of chronic viral hepatitis and blood mercury levels in US reproductive-age women from NHANES 2001-2008: a cross-sectional study. Environmental Health 2012 $11: 62$. 